\title{
Charles Nodier, Promenade de Dieppe aux montagnes d'Ecosse
}

\section{Jean-Nicolas De Surmont}

\section{(2) OpenEdition}

1 Journals

\section{Édition électronique}

URL : http://journals.openedition.org/studifrancesi/8310

DOI : 10.4000/studifrancesi.8310

ISSN : 2421-5856

Éditeur

Rosenberg \& Sellier

\section{Édition imprimée}

Date de publication : 1 mai 2009

Pagination : 193-194

ISSN : 0039-2944

\section{Référence électronique}

Jean-Nicolas De Surmont, « Charles Nodier, Promenade de Dieppe aux montagnes d'Ecosse », Studi

Francesi [En ligne], 157 (LIII | I) | 2009, mis en ligne le 30 novembre 2015, consulté le 13 janvier 2021.

URL : http://journals.openedition.org/studifrancesi/8310; DOI : https://doi.org/10.4000/studifrancesi. 8310

Ce document a été généré automatiquement le 13 janvier 2021.

\section{(c) 9 (i) $\Theta$}

Studi Francesi è distribuita con Licenza Creative Commons Attribuzione - Non commerciale - Non opere derivate 4.0 Internazionale. 


\title{
Charles Nodier, Promenade de Dieppe aux montagnes d'Ecosse
}

\author{
Jean-Nicolas De Surmont
}

\section{RÉFÉRENCE}

CHARLES NODIER, Promenade de Dieppe aux montagnes d'Ecosse, édition établie et commentée par Georges ZARAGOZA, Paris, Champion, 2003, pp. 192.

1 L'occasion s'est imposée pour Honoré Champion de publier Promenade de Dieppe aux montagnes d'Ecosse dans lequel Nodier relate ses souvenirs et impressions d'un voyage effectué en juin 1821. Cet ouvrage s'inscrit dans la lignée de la production antérieure de Nodier composée essentiellement de volumes de souvenirs, épisodes autobiographiques mêlés à des épisodes historiques.

Dans l'introduction, l'auteur de l'édition critique Georges Zaragoza souligne que le premier à avoir écrit sur le sujet est Thomas Pennant (A Tour in Scotland, 1769, Chester, 1771) suivi de peu par le docteur Johnson (A Journey to the Western Isles of Scotland, London, 1775). Les récits de voyage des Français sont redevables à Faujas de Saint-Fond et à Pierre Nicolas Chantreau. Difficile de ne pas déceler un lien flagrant entre l'admiration que porte Nodier pour le romancier Walter Scott et le barde Ossian de MacPherson puisque ces deux derniers sont souvent cités dans le récit. Cela ne l'empêche pas de voir dans l'Ossian de Macpherson une supercherie littéraire. Quant à Scott, on sait qu'après son voyage en Ecosse, Nodier écrit de longs articles en y développant en même temps ses vues sur le roman historique (cfr. p. 157). Ces articles sont publiés dans les annexes du volume (pp. 153 ss.).

3 L'ouvrage de Nodier constitue un pèlerinage littéraire vers les racines du roman historique pour confronter la réalité aux livres dont il s'est abreuvé les années précédentes. La vision de Nodier est en ce sens impressionniste: «La vérité du fait n'a aucune réalité; seule existe la réalité de la perception qu'il en a» (p. 16). 
4 Le récit de voyage commence le 13 juin 1821 à Dieppe. La première entrée est en fait une lettre envoyée à sa femme qu'il tenait au courant des détails de ses déplacements et des rigueurs du climat écossais et britannique. Pour Nodier, la relation de cette promenade se fait sous la forme d'une «histoire de toutes [s]es impressions» (p. 33). L'auteur livre ainsi ses commentaires et remarques sur Dieppe, Brighton, Londres, Edimbourg, etc. La section VI porte ainsi le titre de «Monuments», la section VII celui de «Les Docks-Greenvich», ces immenses bassins où se rendent les vaisseaux, la section IX «Les Musées». D’autres sont plutôt le fait de villes visitées comme Richmond (section IX), Oxford (section X) où il parle des musées et bibliothèques. Parfois, il fait référence aux caractéristiques géomorphologiques des villes comme aux grandes pièces d'architecture. En fait les chapitres thématiques adoptent à peu près la même démarche de journal présentant une ébauche d'observations sur les chapitres portant le nom de villes, mais en ciblant sur des monuments ou des détails du pays. Ainsi le chapitre XVI est consacré à la cathédrale de Glasgow.

5 Le chapitre XXII est remarquable d'une part, parce que c'est l'un des plus longs dans le manuscrit d'origine, d'autre part parce qu'il traite d'entomologie et de botanique, deux des passions de Nodier. Dans le chapitre XXIII intitulé «Le Lac Kattrine», l'auteur décrit la paysannerie et ses relations avec la batelière l'amène à évoquer la tradition orale d'Ecosse rappelant ainsi sa sensibilité et son intérêt pour les traditions nationales non seulement de la France mais aussi de d'autres pays.

6 Le récit de la promenade est suivi de Voyages pittoresques et romantiques dans l'ancienne France qu'il consigne avec J. Taylor et Alph De Cailleux, de quelques lettres envoyées à sa femme Désirée, écrites de Fécamp, notamment, à l'occasion de sa promenade. Les articles consacrés à Walter Scott, publiés à son retour, figurent à la suite. L'ouvrage se termine par des éléments de bibliographie, un index des noms de personnes et de lieux et la table des matières. 